\title{
Behavioral medicine and prevention of non-communicable diseases in China: Current challenges and future directions
}

\section{Ding Ding, ${ }^{1 *}$ Xuefeng Zhong, ${ }^{2,5}$ Joseph Tak-Fai Lau, ${ }^{3}$ Brian Oldenburg ${ }^{4,5}$}

${ }^{1}$ Prevention Research Collaboration, Sydney Medical School \& School of Public Health, University of Sydney, 94 Parramatta Rd, Camperdown, New South Wales, Australia.

*Corresponding author: melody.ding@sydney.edu.au

Tel +61290363332| Fax +61290363184

${ }^{2}$ Institute of Health Education, Anhui Provincial Center for Disease Control and Prevention, Hefei, Anhui, China

${ }^{3}$ The Jockey Club School of Public Health and Primary Care, the Chinese University of Hong Kong

${ }^{4}$ Academic Centre for Health Equity, Melbourne School of Population \& Global Health, University of Melbourne, Victoria, Australia

${ }^{5}$ Global Health and Society Unit, School of Public Health \& Preventive Medicine, Monash University, Melbourne, Victoria, Australia 


\begin{abstract}
Purpose: We describe the emergence of recent public health challenges in China, particularly those related to lifestyle-related non-communicable diseases (NCDs). We also summarize some recent examples of behavioral medicine research and practice in relation to the prevention and control of NCDs in China. Finally, we describe recent changes in the public health system in China and how behavioral medicine research and practice can be incorporated into this system to address these public health challenges.

Methods: We consider research and policy literature from both China and Western countries in order to evaluate the relevance of the field of behavioral medicine for addressing the rising NCDs in China.
\end{abstract}

Results: Rapid economic development and related social and environmental changes have brought about increasing wealth and lifestyle changes in China, along with new public health challenges related to the prevention and control of NCDs. The field of behavioral medicine has much to offer China in addressing these public health challenges. Although the field of behavioral medicine in public health is in its infancy in China, there are encouraging signs of its development, particularly resulting from international collaborations with researchers from Western countries. The next stage of this field's development in China will involve increased integration of behavioral medicine into public health education, training and the health system. However, this process of integration will need to build on China's traditional approaches to public health training, research and practice.

Conclusions: Although the field of behavioral medicine in public health is still in its infancy in China, we argue that the practice and principles of behavioral medicine are important for successfully addressing the very substantial burden of NCDs now and in the future.

Keywords: Public health, non-communicable diseases, behavioral medicine, China, prevention 
With a population of more than 1.3 billion people, China is the world's most populous country and it is now the second largest economy in the world. Its rapid economic progress notwithstanding, China's vast population also contributes significantly to the global burden of disease and the health of many citizens still lags behind its rapid economic growth [1]. In this article, we first discuss the recent emergence of public health challenges in China, particularly those related to non-communicable diseases (NCDs) such as cardiovascular disease and diabetes. We then summarize current behavioral medicine research and practice regarding NCD prevention in western countries and in China and how behavioral medicine could help improve this situation in China. We further describe the public health system in China and discuss the challenges and opportunities involved in advancing the field of behavioral medicine in China.

\section{Economic Growth, Lifestyle Changes and NCDs in China}

Since economic reform commenced in the late 1970s, China has experienced rapid economic growth and urbanization. Since then, China's economy has been growing at a rate of around $10 \%$ per year [2] and the percentage of the population living in urban areas has more than doubled from under $20 \%$ in 1978 to almost $50 \%$ in 2010 [3]. The economic growth and urbanization have contributed to significant improvements in many health indicators in China. For example, between 1970 and 2010, life expectancy rose from 60 to almost 73 years for men and from 63 to 79 years for women, and the under-5 mortality rate declined from 101 to 13 per 1000 [4].

Meanwhile, the total fertility rate has declined from 4.8 to 1.6 children per woman from 1970 to 2010 [5]. In 2010, more than $13 \%$ of the population were aged 60 years and above, compared with only $10 \%$ in 2000 [6] and this trend will continue to increase rapidly for years. The recently 
published Global Burden of Disease, Injuries, and Risk Factors Study revealed a striking transition in disease burden in China from 1990 till 2010. The disease burden (as measured by disability-adjusted life-years) from communicable, maternal, neonatal, and nutritional disorders declined by $67 \%$, while that from NCDs increased by $12 \%$. Indeed, seven of the ten leading causes of years of life lost in China were NCDs in 2010, with these being stroke, ischemic heart disease, chronic obstructive pulmonary disease (COPD), lung cancer, liver cancer, stomach cancer, and esophageal cancer [4]. According to national data, NCDs accounted for an estimated $80 \%$ of deaths and $70 \%$ of the total disease burden in China in $2005[7,8]$. The number of NCD cases among Chinese people over the age of 40 is expected to more than double over the next two decades and the burden of the four leading NCDs (myocardial infarction, stroke, diabetes, and COPD) is expected to increase by almost 50 percent between 2010 and 2030 [9]. China has about one third of the world's diabetes cases and the national prevalence of diabetes and prediabetes among adults in 2010 was $11.6 \%$ and $50.1 \%$, respectively [10].

Evidence from a variety of sources demonstrates that some of the most important contributors to the recent rise of NCDs, particularly cardio-metabolic conditions, are changes in lifestyle behaviors [7,11]. In 2010 the leading behavioral risk factors in China were nutrition and dietary behaviors, smoking, high alcohol use and physical inactivity [4]. Between 1989 and 2004, the proportion of fat in the total dietary energy intake increased from $19 \%$ to $28 \%$ [12]. Meanwhile, most Chinese adults have experienced a significant reduction in physical activity, as the energy expenditure from occupational and domestic sources declined by $23 \%$ and $54 \%$ from 1991 to 2000 [13]. Modes of transportation have also become increasingly inactive as car ownership increased by an average of $20 \%$ per year between the 1990s and 2005 [14]. Television ownership 
and the use of many other screen-based devices have also proliferated in Chinese households, so that leisure-time pursuits have become increasingly sedentary. For example, a recent study found that the proportion of Shanghai elderly who identified TV viewing as the most common leisuretime activity increased from 66\% in 1998 to $78 \%$ in 2008 [15]. As a result of changes in diet, physical activity, and sedentary behavior, the prevalence of overweight and obesity among Chinese adults increased from $23 \%$ and $7 \%$ in 2002 to $31 \%$ and $12 \%$ in 2010 [16].

To address the new public health challenge of lifestyle-related NCDs, it is important for China's health care and public health systems to emphasize on lifestyle changes among China's vast population. To be successful, this will require changes at all levels of society, particularly the living and working environments that facilitate healthy lifestyles. The field of behavioral medicine has much to offer in this regard, from understanding the multi-level influences on behaviors, to developing and evaluating interventions and strategies, and finally, to the translation of interventions to more 'real world' community settings [17].

\section{Behavioral Medicine and the Prevention and Control of NCDs in China}

The International Society of Behavioral Medicine's definition of behavioral medicine emphasizes its interdisciplinary nature: "[it is the] the interdisciplinary field concerned with the development and integration of socio-cultural, psychosocial, behavioral, and biomedical knowledge relevant to health and illness and the application of this knowledge to disease prevention, health promotion, etiology, diagnosis, treatment, and rehabilitation" [18]. This interdisciplinary approach is important for not only informing an understanding of the 
determinants of NCDs, but also for developing an evidence base for multi-level and multisectoral interventions.

Because the rapid increase in NCDs in China is so inextricably linked with its rapid socioeconomic development, it will only be possible to modify individuals' lifestyles by simultaneously addressing the mid- and up-stream policies as well as the social and environmental determinants of health. To achieve this, community-wide and whole-of-society approaches are pivotal and should involve sectors such as urban planning, transportation, environmental protection, food marketing and public policy. These kinds of approaches have been recently highlighted in an important publication in response to the World Health Organisation (WHO)'s ambitious global target to reduce preventable mortality due to NCDs by $25 \%$ by the year 2025 [19].

Over the last 40 years, behavioral medicine researchers, primarily from Western countries, have been at the forefront in building the evidence base to demonstrate that interventions can positively influence lifestyle behaviors and their socio-environmental determinants [20,21]. These interventions have variously targeted individuals, population sub-groups, whole populations, as well as policies, settings and environments. Improving understanding about how health behaviors are influenced by multiple levels of determinants has in turn informed the development of social ecological models, which have subsequently been used to guide interventions [22]. For example, multi-level tobacco control efforts targeting individuals, organizations, environments, social norms, and policies have led to well-evaluated successes in tobacco control in places like California [23]. 
Secondly, behavioral medicine has contributed greatly to the development of evidence-based international behavioral recommendations for prevention and management of NCDs. For instance, a number of randomized control trials have demonstrated that undertaking at least 30 minutes of moderate-to-vigorous physical activities per day reduces risk of developing diabetes by $46 \%$ among those with impaired glucose tolerance [24] and that dietary changes (DASH Dietary Approach to Stop Hypertension diet and reduction in sodium) effectively reduce blood pressure among hypertensive patients [25]. Evidence like this has been used to prepare guidelines for NCD prevention which have been subsequently recommended by international health authorities and then adopted by health care workers in many countries.

Thirdly, the use of socio-behavioral and other theories has informed the development of effective behavioral medicine interventions [26]. In the case of tobacco control, for example, besides social ecological models mentioned above, the Transtheoretical Model has been used intensively and effectively. The model takes into account that people at different stages of change have different needs and wants, therefore different strategies are needed to advance their stages to result in behavioral changes [27]. Many other theories and models, such as social cognitive theory and social marketing theory, have become increasingly used in behavior change interventions.

Finally, recent research in behavioral medicine has increasingly emphasized the development, implementation and evaluation of scaled-up interventions to evaluate the acceptability, feasibility, and cost-effectiveness of efficacious intervention strategies under "real world" conditions [28]. More attention in behavioral medicine is now also being given to translating and evaluating such interventions in more resource-constrained settings and countries [29]. 
Although it seems clear that the approaches and methods of behavioral medicine described above have much to offer to address the burden of NCDs that currently confronts China, they are still at an early stage in China. However, it is easily forgotten that when behavioral medicine was first established as a field in Europe and North America during the 1970s and 1980s, crossdisciplinary collaboration among the medical, public health, social and behavioral sciences was still quite unusual. There are some encouraging signs that interdisciplinary approaches to conducting research and developing interventions are beginning to emerge in China. For example, while tobacco research in China traditionally focused on descriptive epidemiological research, recent social and behavioral epidemiological research has begun to examine correlates and determinants of smoking, such as social influences, cultural practices, marketing strategies, and policies [30]. This kind of research is a prerequisite for developing comprehensive tobacco control strategies in China. Another encouraging sign is the increasing international collaboration in behavioral medicine. For example, one author of this article (XZ) collaborated with a team of multi-disciplinary international researchers to conduct a theory-based intervention trial using a community-based peer support approach for diabetes self-management. The trial results showed significant improvements in diet and physical activity and moderate changes in blood sugar levels [31]. She also worked with Dutch researchers to implement and evaluate a communitybased cardiovascular disease (CVD) prevention program adapted from the Netherlands to modify CVD risk factors, such as diet, physical activity and smoking, among a high-risk population in China. Both of these community-based and theory-based interventions not only emphasized the individuals (e.g., knowledge, attitude, self-efficacy), but also the social environments (e.g., family, friends, and peer support group), communities (e.g., health care providers), and policies (e.g., financial and policy support from the local Health Bureau) [32]. These examples suggest an 
encouraging trend towards the adaptation of behavioral medicine concepts and methods to the prevention and control of NCDs in China.

\section{Integrating Behavioral Medicine into Public Health Training, Policy, and Practice in China}

Although there are some excellent recent examples of the application of behavioral medicine to NCD prevention and control in China, it is important that such approaches are incorporated into the broader health systems in China. However, the application of behavioral medicine in public health is still under-developed in China. For example, to the authors' knowledge, there are still no departments of behavioral medicine or social and behavioral sciences in the majority of schools of public health in China. However, in this regard, it is important to understand the unique history of China's public health system and the training of its workforce.

China's public health system. China has a unique and nationally coordinated Centers for Disease Control and Prevention (CDC) system, which operates at the national, provincial, city, and district/county levels. The latter level of the CDC system is particularly important for disease surveillance as well as the management and delivery of public health and primary care services. The CDC system also has the responsibility for supporting, training, and supervising the Community Health Services Centers and their associated Community Health Services Stations in the delivery of basic primary care, health education, and health promotion.

The current China CDC system was established during 2002-2003 and evolved out of the earlier national system of Anti-Epidemic Stations which were adapted from a system in the former Soviet Union in the early 1950s. The primary task of the Anti-Epidemic Stations was to control 
the spread of infectious diseases. Over time, this system became increasingly incapable to deal with recent challenges from NCDs [33]. Hence, a new national CDC system was formally established to combat NCDs and other emerging public health challenges.

The history of public health training in China. Traditionally, the China CDCs recruit new employees from schools of medicine and schools of public health, usually with a background in medicine, laboratory sciences, statistics, or epidemiology. Unless trained overseas, very few of these employees have received systematic education or training in behavioral or social sciences, such as health psychology, medical sociology, medical anthropology, and health communication science. Employees with any background or inter-disciplinary training in behavioral medicine are even more unusual. Therefore, the lack of staff with training and experience in health behavioral and social sciences limits the capacity of the health care and public health systems to prevent and manage NCDs in China.

When the concept of "public health" was originally adopted from the former Soviet Union, “public health” was translated into Chinese as “public hygiene” (公共卫生), which is a concept that is rather different from the WHO definition of "health" (健康), that is, "a state of complete physical, mental and social well-being and not merely the absence of disease or infirmity" [34]. Within the tradition of public health in China, most of the emphasis was on "public hygiene" as it relates to the control of communicable diseases and public health medicine. Hence, most public health degrees in China have traditionally emphasized training in areas such as epidemiology and biostatistics (流行病学与卫生统计学), environmental hygiene (环境卫生学), 
food and nutrition hygiene (食品与营养卫生学), occupation and labor hygiene (职业与劳动卫

生学), school hygiene (学校卫生学) and radiation hygiene (放射卫生学). In recent years, some

schools of public health have introduced maternal and child health (妇幼与少儿卫生学) and

social medicine (社会医学) [35]. This suggests that there has been much less emphasis on social,

behavioral, and health policy sciences compared with public health training in Western countries over the last 20 years [36]. Indeed, it is still the case that for most postgraduate public health training in China, only individuals with an undergraduate degree in medicine or public health medicine are eligible to apply for admission. However, there are signs that some universities are starting to emphasize bio-behavioral mechanisms (etiology, pathogenesis, and mechanisms of common diseases) and behavioral intervention approaches. Furthermore, the recently published university textbook of Health Education include socio-behavioral theories as key contents [37].

Public health practice in China. Since the 1950s China has a long history of successful health education campaigns directed at infectious disease control and prevention. Traditionally, these programs used the contemporary media of the day and were based on the mobilization of communities and social influence as a way of directing families and communities to take quite specific actions. An example of such campaigns from this era include the "two controls and five changes" campaign (directed at improving the quality of drinking water and the removal of human faeces by improving the sanitation of wells, toilets, cattle-sheds, cooking fires and living environments) [38]. Over the last 60 years this campaign and many others in China have been very successful in the control and prevention of infectious diseases. 
However, the current shift towards NCDs becoming the largest cause of disease burden in China requires more complex, multi-level changes throughout society and communities, while simultaneously encouraging individuals and their families to make healthy lifestyle choices. Such change at an individual level requires supportive policies and health-promoting environments and communities. While there have been an increasing number of programs targeting lifestyle risk factors in China, the main approaches have been health propaganda, traditional information delivery, health education and communication. Most of these programs have focused on raising people's awareness of health and most have used a KAP (Knowledge, Attitude, and Practice) intervention approach. It was not until recently that contemporary theories and models were used to guide intervention development.

China's health care system and health reform. In 2009, the Chinese government initiated a very ambitious health-care reform plan. One of the most important components of the reform is that the government now provides a budget of $¥ 30 /$ person/year (approx. US\$5) to primary care organizations to deliver a defined package of 11 basic public health services. Most of the services in the package are relevant to the prevention and control of NCDs, such as providing health education to residents, and diabetes and hypertension management. Furthermore, in May 2012 the Ministry of Health and 14 other ministries and state administrations in China issued a National Plan for NCDs Prevention and Treatment (2012-2015), which proposed an extensive and ambitious list of strategies to be implemented to slow down and reverse the worsening situation of NCDs over the next 10 years [39]. These components of the heath-care reform have sent positive signals that the Chinese government is now paying more attention to the rising 
epidemic of NCDs. This has provided a good political environment for the development of behavioral medicine in China's public health system to combat rising NCDs.

\section{Conclusions and Recommendations for the Future}

While it is encouraging to see emerging research projects and programs in China that are applying the principles and theories of behavioral medicine, the translation and widespread implementation of these strategies remain limited due to the lack of human resources, knowledge and capacity in the field [40]. Here, we provide some suggestions for the future sustainable development of behavioral medicine in China. Currently, international collaboration and exchange still play an important role in developing this field in China. However, with the increasing internationalization of schools of public health in China, they are sending researchers abroad as visiting scholars. Such exchanges should be facilitated by international institutions through regular fellowships and training programs. The International Society of Behavioral Medicine is in an excellent position to foster these developments, by organizing workshop forums, satellite meetings and pre-conference workshops and special issues of relevant journals. It could also be helpful to establish behavioral medicine centres in major universities in China in order to serve as focal points for international exchange and collaborations. Through such facilitation behavioral medicine approaches will gradually be incorporated into public health practice in China. Combating NCDs will require changes in people's lifestyles and physical and social environments. The authors are confident that the field of behavioral medicine will develop and be incorporated into public health practice in China. 


\section{Statement}

All authors have conformed to the Helsinki Declaration concerning human rights and informed consent, and that they have followed correct procedures concerning treatment of humans and animals in research. All authors declare no conflict of interest.

\section{References}

1. World Health Organization. Country profile: China. Geneva: WHO 2006.

2. The World Bank. GDP growth (annual \%). 2013.

http://data.worldbank.org/indicator/NY.GDP.MKTP.KD.ZG. Accessed 17/10 2013.

3. National Bureau of Statistics of China. China's urbanization rate statistics over the years (1949-2010): National Bureau of Statistic of China 2011.

4. Yang G, Wang Y, Zeng Y, Gao GF, Liang X, Zhou M et al. Rapid health transition in China, 1990-2010: findings from the Global Burden of Disease Study 2010. Lancet.

2013;381(9882):1987-2015.

5. UN Department of Economic and Social Affairs- Population Division. World population prospects: the 2010 revision, vol. 1 \& 2: comprehensive tables. New York: United Nations 2011. 6. Nationl Bureau of Statistics of China. Bulletin of the Sixth National Population Census in 2010 (no.1) 2011. http://www.stats.gov.cn/tjgb/rkpcgb/qgrkpcgb/t20110428_402722232.htm. Accessed Sep 5, 2013.

7. Yang Z-Y, Yang Z, Zhu L, Qiu C. Human behaviors determine health: Strategic thoughts on the prevention of chronic non-communicable diseases in China. Int J Behav Med. 2011;18(4):295-301.

8. Wang L, Kong L, Wu F, Bai Y, Burton R. Preventing chronic diseases in China. Lancet. 
2005;366(9499):1821-4.

9. Wang S, Marquez P, Langenbrunner. Toward a healthy and harmonious life in China:

Stemming the rising tide of non-communicable diseases. Washington D.C.: The World Bank 2011.

10. Xu Y, Wang L, He J, Bi Y, Li M, Wang T et al. Prevalence and control of diabetes in Chinese adults. JAMA. 2013;310(9):948-59.

11. He J, Gu D, Wu X, Reynolds K, Duan X, Yao C et al. Major causes of death among men and women in China. N Engl J Med. 2005;353(11):1124-34.

12. Zhai F, Wang H, Du S, He Y, Wang Z, Ge K et al. Prospective study on nutrition transition in China. Nutr Rev. 2009;67 Suppl 1:S56-61.

13. Monda KL, Adair LS, Zhai F, Popkin BM. Longitudinal relationships between occupational and domestic physical activity patterns and body weight in China. Eur J Clin Nutr. 2008;62(11):1318-25.

14. Li J, Walker J, Srinivasan S, Anderson W. Modeling -private car ownership in China. Transportation Research Record. 2010;2193(-1):76-84.

15. Feng Q, Purser JL, Zhen Z, Duncan PW. Less exercise and more TV: Leisure-time physical activity trends of Shanghai elders, 1998-2008. J Public Health (Oxf). 2011;33(4):543-50.

16. Center for Disease Control and Prevention. Report on Chronic Disease Risk Factor Surveillance in China: Military Medical Science Press 2012. Contract No.:

ISBN:9787802459380.

17. Oldenburg B. Preventing chronic disease and improving health: Broadening the scope of behavioral medicine research and practice. Int Journal of Behavioral Medicine. 2002;9(1):1-16. 18. International Society of Behavioral Medicine. Charter. 2013. 
http://www.isbm.info/html/charter.html. Accessed 20 May 2013.

19. United Nations General Assembly. Political declaration of the High-level Meeting of the

General Assembly on the Prevention and Control of Non-communicable Diseases. New York: United Nations 2011.

20. Knowler WC, Barrett-Connor E, Fowler SE, Hamman RF, Lachin JM, Walker EA et al. Reduction in the incidence of type 2 diabetes with lifestyle intervention or metformin. $\mathrm{N}$ Engl J Med. 2002;346(6):393-403.

21. Eyre H, Kahn R, Robertson RM, Clark NG, Doyle C, Hong Y et al. Preventing cancer, cardiovascular disease, and diabetes: A common agenda for the American Cancer Society, the American Diabetes Association, and the American Heart Association. Stroke. 2004;35(8):19992010.

22. Sallis JF, Owen N, Fisher EB. Ecological models of health behavior. In: Glanz K, Rimer BK, Viswanath K, editors. Health Behavior and Health Education: Theory, Research, and Practice, 4th edition. San Francisco: Jossey-Bass; 2008.

23. Al-Delaimy WD, White MM, Gilmer T, Zhu S-H, Pierce JP. The California Tobacco Control Program: Can we maintain the progress? Results from the California Tobacco Survey, 1990-2005. Volume 1. La Jolla, CA: University of California, San Diego; 2008.

24. Pan XR, Li GW, Hu YH, Wang JX, Yang WY, An ZX et al. Effects of diet and exercise in preventing NIDDM in people with impaired glucose tolerance. The Da Qing IGT and Diabetes Study. Diabetes Care. 1997;20(4):537-44.

25. Sacks FM, Svetkey LP, Vollmer WM, Appel LJ, Bray GA, Harsha D et al. Effects on blood pressure of reduced dietary sodium and the Dietary Approaches to Stop Hypertension (DASH) Diet. New Engl J Med. 2001;344(1):3-10. 
26. Noar SM, Zimmerman RS. Health Behavior Theory and cumulative knowledge regarding health behaviors: are we moving in the right direction? Health Educ Res. 2005;20(3):275-90. 27. Aveyard P, Massey L, Parsons A, Manaseki S, Griffin C. The effect of Transtheoretical Model based interventions on smoking cessation. Soc Sci Med. 2009;68(3):397-403.

28. Beaglehole R, Bonita R, Horton R, Adams C, Alleyne G, Asaria P et al. Priority actions for the non-communicable disease crisis. Lancet. 2011;377(9775):1438-47.

29. van de Vijver S, Oti S, Addo J, de Graft-Aikins A, Agyemang C. Review of communitybased interventions for prevention of cardiovascular diseases in low- and middle-income countries. Ethn Health. 2012;17(6):651-76.

30. Ding D, Gebel K, Oldenburg B, Wan X, Zhong X, Novotny T. An early-stage epidemic: A systematic review of correlates of smoking among Chinese women. Int J Behav Med. In press. doi:10.1007/s12529-013-9367-1.

31. Zhong X. Peer support interventions for diabetes and community health centers in China. International Congress of Behavioral Medicine; Budapest 2012.

32. Fisher EB, Zhong X, Kowitt S, Nan H. The importance of contexts and the roles of community and peer support programs in bridging gaps among contexts, self-management interventions, and clinical care. In: J Rodriguez-Saldana, editor. Quality of Health Care: Challenges, Evidence and Implementation. 2014.

33. Horton R. China's major health challenge: control of chronic diseases. Lancet. 2011;378(9790):457.

34. World Health Organization. WHO definition of health. 1946.

http://www.who.int/about/definition/en/print.html. Accessed Sep 1, 2013.

35. Liu J. From public hygiene to public health: The paradigm shift of China's public health 
policy and its challenges. Shanghai People's Publication House; 2007.

36. Wang Q, Kang F, Song W, Li L. Thoughts on reform of the Chinese health education system (in Chinese). Medical Education. 2001;1(2).

37. Ma X. Health Education (in Chinese). Beijing: People's Medical Publishing House; 2012.

38. Horn JS. Away with all pests: An English Surgeon in People's China, 1954-1969. New York: Monthly Review Press; 1971.

39. Chinese Center for Disease Control and Prevention. The China National Plan for NCD Prevenion and Treatment (2012-2015). 2012. http://www.chinacdc.cn/en/ne/201207/t20120725_64430.html. Accessed Oct. 302013. 40. Lv J, Liu M, Jiang Y, Li LM. Prevention and control of major non-communicable diseases in China from 1990 to 2009: Results of a two-round Delphi survey. Glob Health Action. 2013;6:20004. 